\title{
Atık Taşıma Yolu Olarak Kanalların Uygunluk Analizi (Endonezya'daki Makassar Şehri Örneği)
}

\author{
Muhammad Irfan ${ }^{1 *}$, Ramdan Pano ${ }^{2}$ \\ $\mathbf{1}^{*}$ Akdeniz Üniversitesi, Fen Bilimler Enstitüsü, Şehir ve Bölge Planlama Bölümü, Antalya, Türkiye, (ORCID: 0000-0003-4629-5943), muhirfanfaizal@gmail.com \\ ${ }^{2}$ University of Debrecen, Mühendişlik Fakültesi, Kentsel Sistem Mühendişliği, Debrecen, Macaristan (ORCID: 0000-0002-9722-0186), ramdanpano@gmail.com
}

(1st International Conference on Applied Engineering and Natural Sciences ICAENS 2021, November 1-3, 2021)

(DOI: 10.31590/ejosat.1009140)

ATIF/REFERENCE: Irfan, M. \& Pano, R. (2021). Atık Taşıma Yolu Olarak Kanalların Uygunluk Analizi. Avrupa Bilim ve Teknoloji Dergisi, (28), 557-561.

\section{$\ddot{O} \mathbf{z}$}

Makassar'daki gecekondu yerleşimleri şu anda bir sorun olarak görülüyor. Bölgedeki altyapı eksikliğinin yanı sıra nehir kıyısındaki durumu da köyün gecekondulaşmasına neden oluyor. Katı atık altyapısı, atık taşıma modlarına erişimi zorlaştıran sıkışık koşullar ve dar erişim noktaları ile ilgili sorunlardan biridir. Bu nedenle, gecekondulardaki atık sorunlarının üstesinden gelebilecek ve zorluklara cevap verebilecek etkin ve verimli atık taşıma yenilikleri bulmak gerekiyor. Bu çalışma, kanalın Makassar şehrinde bir atık taşıma güzergahı olarak uygulanabilirliğini belirlemeyi amaçlamaktadır. Gözlem ve literatür taraması yoluyla birincil veriler ve ikincil veriler şeklinde elde edilen veriler. $\mathrm{Bu}$ çalışma, bir atık taşıma rotası olarak kanalın fizibilitesini analiz etmek için SWOT yöntemi yaklaşımını kullanmaktadır. Bu çalışmanın sonuçları, Makassar Şehrinde kanalların atık taşıma rotası olarak kullanılmasının fizibilitesinin analizinin sonuçlarıdır. Sonuçlar Yapılan SWOT analizine dayalı olarak, IFAS sonuçlarının Jongaya Kanalı'nın kanal üzerinden atık taşımacılığı için yenilikçi planlama yapma gücüne sahip olduğunu gösterdiği, EFAS sonuçları ise böyle bir planlamayı gerçekleştirme firsatının daha büyük olduğunu göstermektedir. tehditten daha. Bu araştırmanın, atık taşımacılığı için bir erişim noktası olarak kanalın yeni bir imajını oluşturması bekleniyor.

Anahtar Kelimeler: Kanal, Çöp Ulaşımı, Uygunluk Analizi, SWOT Analizi, Makassar Şehri.

\section{Suitability Analysis of the Canal as A Waste Transportation Route (Case Study: Makassar City, Indonesia)}

\begin{abstract}
Slum settlements in Makassar are currently seen as a problem. Due to the lack of infrastructure along the river banks, this condition leads the surrounding neighborhood to become slum spots. Solid waste infrastructure is one of the problems with congested conditions and narrow access points making it difficult to access by waste transport modes. Therefore, it is necessary to find effective and efficient waste transportation innovations, which are able to overcome waste problems and answer challenges in slums. This study aims to determine the feasibility of the canal as a waste transportation route in Makassar City. The data obtained in the form of primary data and secondary data through observation and literature review. This study uses the SWOT method approach to analyze the feasibility of the canal as a waste transportation route. The results of this study are analysis of the feasibility of using canals as a waste transportation route in Makassar City. Results Based on the SWOT analysis carried out, it was found that the IFAS results show the Jongaya Canal has the power to carry out innovative planning for waste transportation through the canal, while the EFAS outcomes show that the opportunity to carry out such planning is greater than the threat. This research is expected to create a new image of the canal as an access point for waste transportation.
\end{abstract}

Keywords: Canal, Waste Infrastructure, Suitability Anlaysis, SWOT Analysis, Makassar City.

\footnotetext{
*Sorumlu Yazar: muhirfanfaizal@gmail.com
} 


\section{Giriş}

Turner'a (1972) göre Kampung, kamu tesislerinin yetersiz olduğu veya hiç bulunmadığı bir gecekondu bölgesidir, genellikle bu alana "gecekondu" veya "gecekondu" denir. Bu arada, Herlianto'ya (1986:42) göre Kampung-Kota, homojen bir nüfusa sahip hala güçlü geleneksel özelliklere sahip ve genellikle hala tarıma yönelik olan kırsal alanları gösteren bir ortamdır. Kampung-Kota aslında kent içinde kırdan kent yaşamına, tarımdan uzmanlığa, gelenekselden moderne, karşılıklı işbirliğinden bürokratik yapıya geçişlerin olduğu, kişisel ilişkilerin temel niteliklere dönüştüğü bir alandır.

$\mathrm{Bu}$ uzmanlardan bazılarının açıklamalarından Kampung Kota'nın, nüfusunun çoğunluğunun hala köy yaşamının (geleneksel) özelliklerini, gecekondu ortamının özelliklerini taşıdığı ve hala sanitasyon ve hijyen tesislerinden yoksun olduğu bir kentsel yerleşim olduğu sonucuna varılabilir. Sonuç olarak, Kampung Kota genellikle gecekondu yerleşimleriyle eşittir.

Kampung Biringkanal, Makassar Şehri, Rappocini Bölgesi, Maricaya Baru Köyü ve Rappocini Köyü'nde bulunan "Kampung Kota" özelliklerine sahip bir yerleşim yeridir. Biringkanal isminin kanalın biring/yan/kenarında bir anlamı vardır. Bunun nedeni, Biringkanal Köyü'nün, Makassar Şehrindeki büyük su akışlarından biri olan Jongaya Kanalı'nın bir toplama alanı olmasidır.

Biringkanal Köyü'ndeki temel sorunlardan biri de atık sorunu, özellikle atık taşımacılığı. Dar yol ağı ve kalabalık ortam, Biringkanal Köyü'nü çöp kamyonları için ulaşılmaz kılıyor. Sonuç olarak, topluluk tarafından toplanan çöpler insanların evlerinin etrafında ve hatta kanal kıyılarında yığılıyor. Bu nedenle, atık sorunlarının üstesinden gelebilecek ve Kampung Kota'nın gecekondu olmak zorunda olmadığı sorununa cevap verebilecek etkin ve verimli atık taşıma yenilikleri bulmak gerekiyor.

Araştırmacı, yukarıdaki açıklamaya dayanarak, doğru çözüm olarak Jongaya Kanalı'nı seçti. Kanal atık taşıma güzergahı olarak kullanılarak, Biringkanal Köyü'nden gelen çöplerin TSK'ya taşınması için yolun darlığı engel teşkil etmemektedir. Bu plan, Makassar Şehrindeki gecekondu yerleşimlerinin üstesinden gelmek için bir çözüm.

\section{Materyal ve Metot}

\subsection{Araştırma Kapsamı}

Bu çalışma, gecekondu yerleşimlerinin, yani atık sorununun, özellikle atıkların taşınması sorununun çözümüne odaklanmaktadır. Ana odak, atık taşıma güzergahı olarak planlanan Jongaya Kanalı'dır.

Araştırma alanı genel olarak Güney Sulawesi, Makassar Şehri, Rappocini İlçesi, Maricaya Baru Köyü'nde bulunan Biringkanal Köyü ve Rappocini Köyü'ndeki kanal boyunca yer alan yerleşimlerdir.

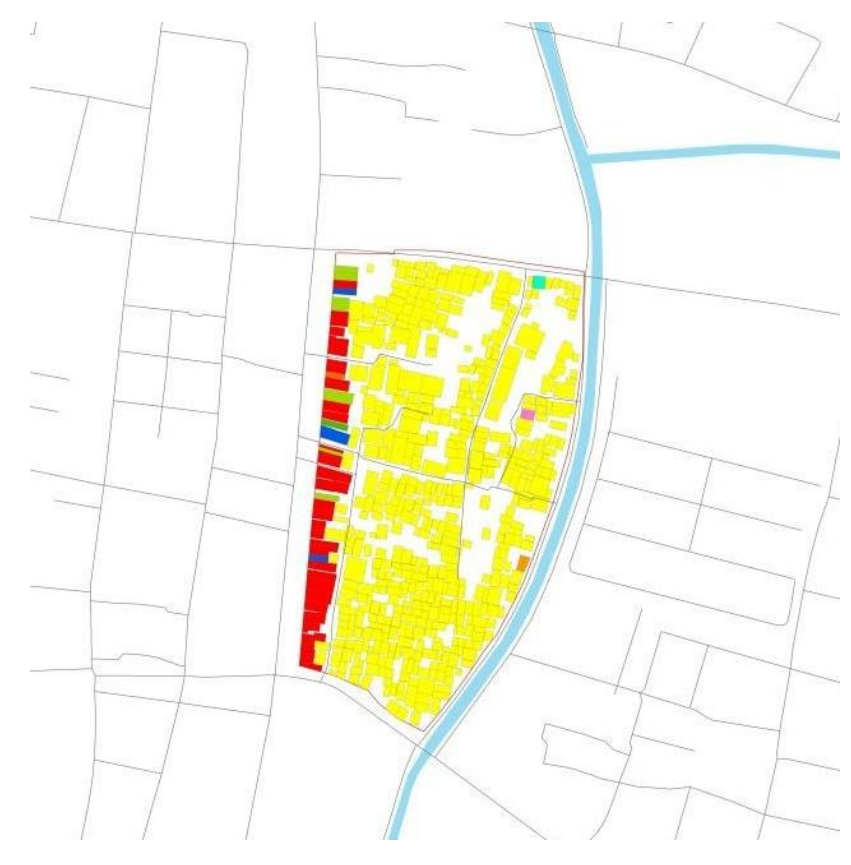

Şekli 1. Çalışmanın Kapsamı

Kaynak: Yazar Belgesi, 2021

\subsection{Veri Toplama Yöntemi}

$\mathrm{Bu}$ çalışmada çeşitli kaynaklardan elde edilen birincil ve ikincil veriler şeklinde elde edilen veriler.

a. Kanalın genişliği, kanalın yüksekliği, kanalın yüksekliği ve kanal çevresinin tanımına ilişkin veriler, gözlem ve ölçüm yöntemleri, yani kanalı ölçmek için çalışma alanına doğrudan ziyaretler ve aynı zamanda kanalın ölçülmesi ile elde edilmiştir. Kampung Biringkanal'ın durumunu gözlemlenmektedir.

b. Araştırma ile ilgili diğer veriler kitap kaynaklarından, web sitelerinden, tezlerden ve bilimsel dergilerden literatür çalışmaları yoluyla elde edilir.

\subsection{Veri Analiz Yöntemi}

Bu çalışmada kullanılan veri analiz yöntemi, kanalın bir atık taşıma güzergahı olarak uygulanabilirliğini analiz etmek olup, bir SWOT analizi yapılarak, Strength (güç), Weakness (zayıflık), Opportunity (Frrsat), dan Treat (Tehdit). SWOT analizi, karşılaşılan tüm zayıflıkları ve tehditleri en aza indirirken, mevcut tüm güçlü yönleri ve açık firsatları en üst düzeye çıkaracak yöntemleri belirlemek.

\section{Araştırma Sonuçları ve Tartışma}

\subsection{Kanal Fizibilite İçin Swot Analizi}

Kanal koşullarının SWOT analizi, Makassar Şehri, Biringkanal Köyü'nde var olan çevre sorunlarının üstesinden gelmek için doğru stratejiyi belirlemek için kullanılan yöntemlerden biridir. Kanal çevre koşullarının üstesinden gelmede strateji belirleme adımlarından biri, güçlü yönler, zayıf yönler, firsatlar ve tehditlerin yorumlanması yoluyla iç ve dış faktörleri yorumlamaktır. SWOT yöntemini kullanan analiz, SWOT kadranındaki konumunu belirlemek için IFAS (Dahili Stratejik Faktörler Analizi Özeti) ve EFAS'ın (Dış Stratejik Faktörler Analizi Özeti) inceleme sürecinden geçer. 


\section{İç Faktörler}

1. Atık Taşıma Yolu Olarak Kanalın Fizibilite

a) Kanal Genişliği Uygunluğu

Kanaldan çöp taşıyan gemilerin geçip geçmediğini tespit edebilmek için dikkat edilmesi gereken şeylerden biri kanalın genişliğidir. $\mathrm{Bu}$ analiz sayesinde genişliğine göre kullanıma uygun olan gemi tipini belirlemek mümkündür. Dahlan'a (2013) göre gemilerin geçmesine uygun kanal genişliğini belirlemek için ideal mesafenin hesaplanması aşağıdaki şekilde anlatılmaktadır:

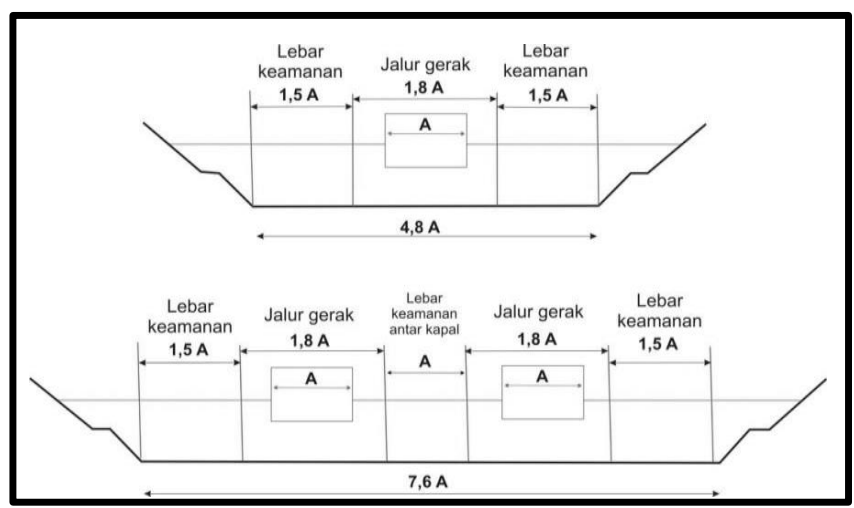

Şekli 2. Ulaşım Güzergahı Olarak Yeterli Genişlikte Kanallar Kaynak: Ahmad Dahlan, 2013

$\mathrm{Bu}$ ideal standartlara dayanarak, aşağıdaki denklemler kullanılabilir:

1 Şeritli Gemi İle

Nehir Değer Genişliği $=4,8 \mathrm{~A}$

Kanalın minimum genişliği $=6 \mathrm{~m} ; 6 \mathrm{~m}=4,8 \mathrm{~A} ; \mathrm{A}=1.25 \mathrm{~m}$

Maksimum genişlik $=16 \mathrm{~m}$

$16 \mathrm{~m}=4,8 \mathrm{~A} ; \mathrm{A}=3.33 \mathrm{~m}$

2 Şeritli Gemi İle

Minimum genişlik $=6 \mathrm{~m} ; 6 \mathrm{~m}=7.6 \mathrm{~A} ; \mathrm{A}=0,8 \mathrm{~m}$

Maksimum genişlik $=16 \mathrm{~m} ; 16 \mathrm{~m}=7.6 \mathrm{~A} ; \mathrm{A}=2,1 \mathrm{~m}$

Tablo 1. Çöp Taşıma Gemisine Uygun Genişlik

\begin{tabular}{ccc}
\hline No & Şerit Sayısı & Gemiye Uygun Genişlik \\
\hline 1 & 1 Şerit & $1,25 \mathrm{~m}-3,33 \mathrm{~m}$ \\
2 & 2 Şerit & $0,8 \mathrm{~m}-2,1 \mathrm{~m}$ \\
\hline
\end{tabular}

Kaynak: Yazarın Analiz Sonuçları, 2021

Tablo 2. Kanal Genişliğine Göre Kanal Uygunluğu

\begin{tabular}{|c|c|c|c|c|c|c|c|}
\hline \multirow[t]{2}{*}{ No } & \multirow[t]{2}{*}{ Gemi Adı } & \multirow{2}{*}{$\begin{array}{l}\text { Gemi Genişliği } \\
\text { (m) }\end{array}$} & \multicolumn{2}{|c|}{ Makul Genişlik (m) } & \multirow{2}{*}{$\begin{array}{c}\text { Kanal } \\
\text { genişligi } \\
(\mathrm{m})\end{array}$} & \multicolumn{2}{|c|}{ Ek Bilgi } \\
\hline & & & 1 şerit & 2 şerit & & 1 şerit & 2 şerit \\
\hline 1. & Kapal Cepat & $1,7 \mathrm{~m}$ & $8,16 \mathrm{~m}$ & $12,92 \mathrm{~m}$ & \multirow{4}{*}{$\begin{array}{c}6-16 \\
m\end{array}$} & MÜMKÜN & MỚMKÖN \\
\hline 2. & Kapal Jukung & $2 \mathrm{~m}$ & $9,6 \mathrm{~m}$ & $15,2 \mathrm{~m}$ & & MƯMKÜN & MỚMKÖN \\
\hline 3. & Kapal Katinting & $0,7 \mathrm{~m}$ & $3,6 \mathrm{~m}$ & $5,32 \mathrm{~m}$ & & LAYIK & LAYIK \\
\hline 4. & Kapal Jolloro & $0,9 \mathrm{~m}$ & $4,32 \mathrm{~m}$ & $6,82 \mathrm{~m}$ & & LAYIK & LAYIK \\
\hline
\end{tabular}

Kaynak: Yazarın Analiz Sonuçları, 2021
Yukarıdaki hesaplamalardan yola çıkılarak tek şeritte kullanılabilen gemi genişliğinin 1,25 - 3,33 m, iki sıra için ise 0,8 $\mathrm{m}-2,1 \mathrm{~m}$ aralığında olduğu sonucuna varılmıştır. Kullanıma uygun gemi türleri Katinting Gemileri ve Jolloro Gemileridir, bu nedenle atıkların taşınması için bu genişlikte çöp taşımak için kullanılabilir veya tasarlanabilir.

b) Kanal Derinlik Fizibilite

Kanal derinliği fizibilite analizi, birkaç değişkeni toplayarak kullanmak istediğiniz ulaşım modunun türüne göre ideal kanal derinliği miktarını belirleme yöntemidir. Genel olarak nakliye şeritlerinin derinliği aşağıdaki formül kullanılarak belirlenebilir:

$\mathrm{H}=\mathrm{d}+\mathrm{G}+\mathrm{R}$

$\mathrm{H}=$ Oluk derinliği (metre)

$\mathrm{d}=$ gemi draftı (metre)

$\mathrm{G}=$ geminin dalgalar ve çömelmeler nedeniyle dikey hareketi (m)

$\mathrm{R}=$ için net özgürlük alanı:

Havuz, gemi draftının \%7-15'i

Gemi draftının \%10-15'i kadar akış

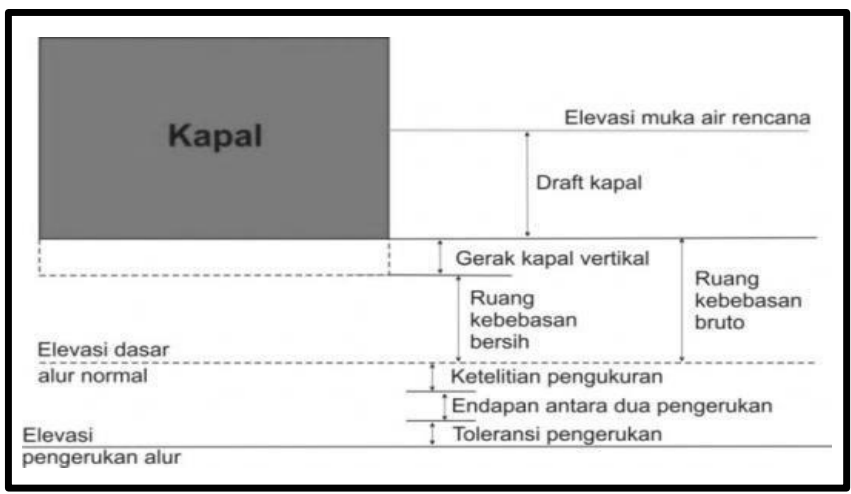

Şekli 3. Kanal Yüksekliğ i

Kaynak: Ahmad Dahlan, 2013

Tablo 3. Gemi Türüne Göre Kanal Uygunluğu

\begin{tabular}{llccccc} 
No & Gemi Adı & $\begin{array}{c}\text { Gemi Taslağı } \\
(\mathbf{m})\end{array}$ & $\begin{array}{c}\text { Temiz } \\
\text { Özgürlük } \\
\text { Odası }(\mathbf{R})\end{array}$ & $\begin{array}{c}\text { İyi Derinlik } \\
(\mathbf{m})\end{array}$ & $\begin{array}{c}\text { Kanal } \\
\text { Derinliği } \\
(\mathbf{m})\end{array}$ & Ek \\
\hline 1. & Kapal Speed & $0,6 \mathrm{~m}$ & $0,06-0,09 \mathrm{~m}$ & $0,89 \mathrm{~m}$ & & Yapabilmek \\
\hline 2. & Kapal Jukung & $0,8 \mathrm{~m}$ & $0,08-0,12 \mathrm{~m}$ & $1,12 \mathrm{~m}$ & & $\overline{\text { Yapabilmek }}$ \\
\hline 3. & Kapal Katinting & $0,4 \mathrm{~m}$ & $0,03-0,045 \mathrm{~m}$ & $0,66 \mathrm{~m}$ & $2-3,5 \mathrm{~m}$ & $\overline{\text { Yapabilmek }}$ \\
\hline 4. & Kapal Jolloro & $0,4 \mathrm{~m}$ & $0,04-0,06 \mathrm{~m}$ & $0,66 \mathrm{~m}$ & & $\overline{\text { Yapabilmek }}$ \\
\hline
\end{tabular}

Kaynak: Yazarın Analiz Sonuçları, 2021

Yukarıdaki tablodan, Makassar kentindeki Jongaya kanalının derinliğinin sürat tekneleri, jukung tekneleri, katinting gemileri ve jolloro gemileri tarafından geçilebileceği sonucuna varılabilir. Ancak kanalın derinliği ile ilgili bir diğer sorun, özellikle kanalın yerleşim yerinin tam karşısında olan kısmında, kanal muayene yolu ile sınırlandırılmadan oldukça yüksek sedimantasyon oluşmasıdır.

c) Köpru Altındaki Boş Alan Fizibilite Analiz

Köprünün altındaki boş alanın fizibilite analizi, bu çalışmanın lokasyonu boyunca çok sayıda köprü bulunması nedeniyle ölçülmesi gereken değişkenlerden biridir, bu yöntem köprü ile su seviyesi arasındaki mesafeyi ölçerek gerçekleştirilmektedir. deniz suyunun en yüksek gelgit anında 
kanal, daha sonra dikey hareket alanı ile karşılaştırarak. su üzerinde gemi. Daha fazla ayrıntı için aşağıdaki resme ve formüle bakınKöprünün altındaki boş alanın fizibilite analizi, bu çalışmanın lokasyonu boyunca çok sayıda köprü bulunması nedeniyle ölçülmesi gereken değişkenlerden biridir, bu yöntem köprü ile su seviyesi arasındaki mesafeyi ölçerek gerçekleştirilmektedir. deniz suyunun en yüksek gelgit anında kanal, daha sonra dikey hareket alanı ile karşılaştırarak. su üzerinde gemi. Daha fazla ayrıntı için aşağıdaki resme ve formüle bakın.

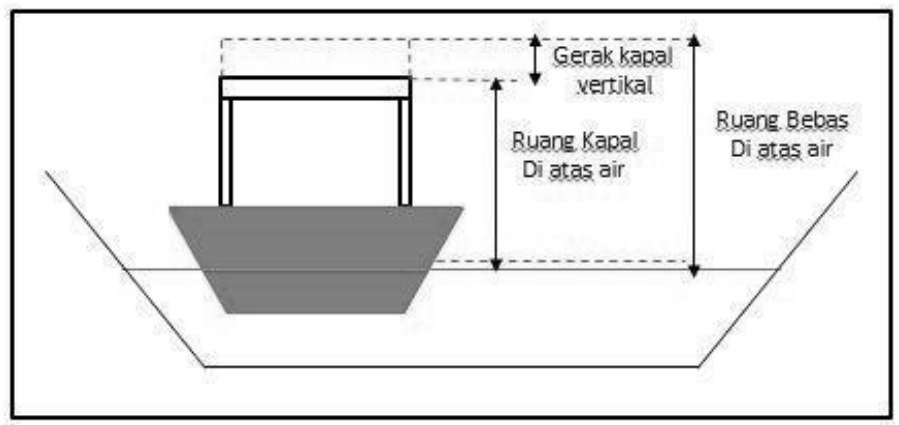

Şekli 4. Su Üzerindeki Gemilerin Boş Alanı. Kaynak : Ahmad Dahlan, 2013

Verilen: Dalga ve çömelme nedeniyle Geminin Dikey Hareketi $=0,2 \mathrm{~m}$

Tablo 4. Köprü Altı Boş Alan Fizibilite Analizi

\begin{tabular}{|c|c|c|c|c|c|}
\hline No & Gemi Adı & $\begin{array}{l}\text { Suda Uzay } \\
\text { Gemisi (m) }\end{array}$ & $\begin{array}{l}\text { Geminin Su } \\
\text { Uzerinde Serbest } \\
\text { Hareketi } \\
\text { (m) }\end{array}$ & $\begin{array}{c}\text { Köprünün } \\
\text { Altında Boş Alan } \\
\text { (m) }\end{array}$ & Ek \\
\hline 1. & Kapal Speed & $1,3 \mathrm{~m}$ & $1,5 \mathrm{~m}$ & \multirow{4}{*}{$0,8-1,4 \mathrm{~m}$} & $\begin{array}{c}\text { Mümkün } \\
\text { değildir }\end{array}$ \\
\hline 2. & Kapal Jukung & $2,2 \mathrm{~m}$ & $2,4 \mathrm{~m}$ & & $\begin{array}{c}\text { Mümkün } \\
\text { değildir }\end{array}$ \\
\hline 3. & Kapal Katinting & $0,4 \mathrm{~m}$ & $0,6 \mathrm{~m}$ & & Mümkün \\
\hline 4. & Kapal Jolloro & $0,7 \mathrm{~m}$ & $0,9 \mathrm{~m}$ & & $\begin{array}{c}\text { Mümkün } \\
\text { değildir }\end{array}$ \\
\hline
\end{tabular}

Kaynak: Yazarın Analiz Sonuçlarl, 2021

Makassar Şehri, Jongaya Kanalı üzerindeki köprünün altındaki boş alana kıyasla geminin su üzerindeki boş alanının analizine dayanarak, geçmeye uygun gemiler katinting gemileri veya üzerinde yaklaşık $0,4 \mathrm{~m}$ boş alana sahip çöp gemileridir. su, gemiler ise mevcut köprüyü geçemedikleri için diğerleri mümkün değildir. Mevcut köprünün yüksekliğini artırarak kanaldaki köprünün altındaki boş alanı artırmak da dahil olmak üzere, bu sorunun üstesinden gelebilecek birkaç önlemin alınması gerekir, böylece gelgitte su yüzeyi ile köprü arasındaki mesafe daha iyi hale gelir. diğer gemiler tarafından göz ardı edilebilmesi için daha büyük. Jolloro gemilerinde 1 metreye, Speed gemilerinde 1,6 metreye, jukung gemilerinde ise 2,5 metreye çıkarılmıştır.
Tablo 5. İç Faktör Ă̆ırlıklandırma ve Puanlama

\begin{tabular}{|c|c|c|c|c|c|c|c|}
\hline \multirow[t]{2}{*}{ No } & \multirow{2}{*}{$\begin{array}{l}\text { Derecelendirme } \\
\text { Parametreleri }\end{array}$} & \multicolumn{3}{|c|}{ Strength } & \multicolumn{3}{|c|}{ Weakness } \\
\hline & & Puan & Ăğılık & Toplam & Puan & Ağırlık & Toplam \\
\hline 1 & $\begin{array}{l}\text { Gemilerin geçebileceği kanal } \\
\text { genișliği }\end{array}$ & 8 & 5 & 40 & & & \\
\hline 2 & Yeterli kanal derinliği & 8 & 5 & 40 & & & \\
\hline 3 & $\begin{array}{l}\text { Birkaç noktada bir köprünün } \\
\text { varlı̆ıı, böylece gemideki boș } \\
\text { alanı azaltıyor }\end{array}$ & & & & 5 & 5 & 25 \\
\hline & Sedimantasyon \%20'ye ulașır & & & & 8 & 3 & 24 \\
\hline & Atıklardan Kanal Kirliliği & & & & 6 & 5 & 30 \\
\hline 6 & IPAL Altyapısı varlığı & 5 & 3 & 15 & & & \\
\hline & $\begin{array}{l}\text { Kanalın akışında Yabani } \\
\text { Otlar ve Çöpler varlığı }\end{array}$ & & & & 4 & 3 & 12 \\
\hline Tot & & & 95 & & & 91 & \\
\hline $\mathbf{S}-$ & $W=95-91=4$ & & & & & & \\
\hline
\end{tabular}

Kaynak: Yazarın analizinin sonuçları, 2021

Tablo 6. Dış Faktör Ağırlıklandırma ve Puanlama

\begin{tabular}{|c|c|c|c|c|c|c|c|}
\hline \multirow{2}{*}{ No } & \multirow{2}{*}{$\begin{array}{c}\text { Derecelendirme } \\
\text { Parametreleri }\end{array}$} & \multicolumn{3}{|c|}{ Opportunity } & \multicolumn{3}{|c|}{ Treat } \\
\hline & & Puan & Ağırlık & Toplam & Puan & Ağırlık & Toplam \\
\hline 1 & $\begin{array}{l}\text { Temizliğin korunmasının } \\
\text { önemi konusunda artan } \\
\text { kamuoyu bilinci }\end{array}$ & 8 & 3 & 24 & & & \\
\hline 2 & $\begin{array}{l}\text { Makassarta Tidak Rantasa } \\
\text { politikasının } \\
\text { programlarından biri } \\
\text { olmak mümkün }\end{array}$ & 9 & 5 & 45 & & & \\
\hline 3 & Sel olasılı̆̆ 1 & & & & 7 & 4 & 28 \\
\hline 4 & $\begin{array}{l}\text { Öngörülemeyen işletme } \\
\text { maliyetleri }\end{array}$ & & & & 6 & 2 & 12 \\
\hline Tota & & & 69 & & & 40 & \\
\hline
\end{tabular}

Kaynak: Yazarın analizinin sonuçları, 2021

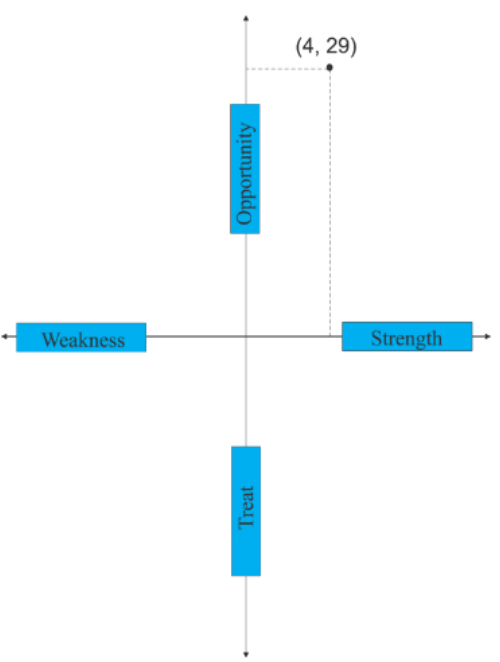

Şekli 5. SWOT Analiz Ë̆risi

Kaynak: Yazarın analizinin sonuçlarl, 2021 
SWOT analizine dayanarak, IFAS sonuçlarının Biringkanal Köyü'nün kanal yoluyla atık taşımacılığı için yenilikçi planlama yapma gücüne sahip olduğunu gösterdiği, EFAS sonuçlarının ise böyle bir planlamayı gerçekleştirme firsatının tehditten daha büyük olduğunu gösterdiği tespit edildi. $\mathrm{Bu}$ nedenle atılması gereken adım, ilerici bir stratejidir, yani sahip oldukları güçlü yönleri ve firsatları desteklemek için sağlam stratejiler uygulayarak. Stratejik adımlar aşağıdaki gibidir:

1. Biringkanal Köyü'nde etkin ve verimli bir şekilde uygulanabilmesi için sağlam bir konsept şeklinde bir plan yapmaktadır.

2. Planlamayı destekleme ve uygulamada toplum katılımını artırmaktadir.

\section{Sonuç}

Yenilikçi Atık Taşıma Sistemi: Kanalların Makassar Şehri, Biringkanal Köyü'nde Atık Taşıma Yolu Olarak Kullanılması tarafindan yapılan analizin sonuçlarına dayanarak, aşağıdaki sonuçlara ulaşılmıştır:

1. Analiz sonuçlarına göre atık taşıma güzergahı olarak kanalın fizibilitesinin belirlenmesinde dikkate alınan faktörler; kullanılabilecek geminin genişliği, kanalın derinliği, geminin su üzerindeki boş alanı, ve kanalın çevresel koşulları.

2. SWOT analizine dayalı olarak, IFAS sonuçlarının Biringkanal Köyü'nün kanal yoluyla atık taşımacılığı için yenilikçi planlama yapma gücüne sahip olduğunu gösterdiği, EFAS sonuçlarının ise bu tür bir planlamayı gerçekleştirme firsatının öncekinden daha fazla olduğunu gösterdiği bulunmuştur. tehdit. Bu nedenle atılması gereken adım, ilerici bir stratejidir, yani sahip oldukları güçlü yönleri ve firsatları desteklemek için sağlam stratejiler uygulayarak.

\section{Kaynakça}

Dahlan, Ahmad. (2013). Makassar Şehrinde Jongaya ve Panampu Kanallarının Su Taşımacılığı Olarak Kullanımına İlişkin Ön Çalışma. Hasanuddin Üniversitesi Öğrenci Bitirme Projesi Dergisi.

Kodoatie, Robert. (2005). Altyapı Yönetimine Giriş. Yogyakarta: Öğrenci Kütüphanesi.

Komala, Sri Puti et al. (2012). Padang Şehri Atık Taşıma Sisteminin Verimliliğinin Analizi. Andalas Üniversitesi.

Setyaningrum, Endang. (2004). İsveç'te Atık Yönetimi Dersleri. Praswil Departmanı Metropolitan Kent Müdürlüğü.

Sihombing, William Iskandar. (2004). Kuzey Sumatra Üniversitesi. Medan Şehrindeki Atık Taşımacılığının Analizi (Örnek Olay: Medan Şehri Bölgesi)

Damanhuri, Enri. (2010). Atık Yönetimi Üzerine Diktat Dersi. Bandung Teknoloji Enstitüsü.

Ambariski, Prismedia Putri. (2016). On Kasım Teknoloji Enstitüsü. Batı Surabaya'da Taşıma Aracı Kapasitesi ve Atık Konteyner Koşullarına Dayalı Çöp Taşıma Sistemi. ITS Mühendislik Dergisi Cilt. 5, Hayır. 2. 2016

Suprajaka. Tangerang Şehrinde Coğrafi Bilgi Sistemi (CBS) Kullanılarak Atık Taşıma Modelinin Optimizasyonu Çalışması. Şehir ve Bölge Planlama Mühendisliği, Esa Unggul Üniversitesi, Jakarta.
(2015). Şehir ve Bölge Planlamada SWOT Analizi. 20 A ğustos 2021 'de (http://www.radarplanologi.com/2015/11/analysis-swotdalam-planning-region-dan-kota.html) adresinden erişildi. 